\title{
The cellular interpretation of anaphylaxis and immunity.
}

\section{By RICHARD WeIL.}

\section{[From the Cornell University Medical College, N. Y. City.]}

It has been shown in previous communications that the serological evidence is not in harmony with the current view that anaphylaxis is due to a reaction between the antibody present in the blood and the introduced antigen. This contention has now been confirmed with the help of the graphic method introduced by Dale, by means of the following experiment. A guinea-pig which is passively sensitized by the injection of 0.3 cubic centimeters of the serum of a rabbit immunized against horse serum, may be killed on the following day by an intravenous injection of horse serum. The uterine preparation also, on the second day, responds typically to the administration of horse serum. If, however, the antigen is applied immediately after sensitization, no reaction occurs, either in vivo or in vitro. The same failure to react follows the injection of relatively enormous amounts of the immune rabbit's serum, as for example three cubic centimeters. Hence, it is apparent that the presence of immune bodies in the circulating blood does not suffice to make a guinea-pig hypersensitive, but that these antibodies must first be bound by the body cells.

In the present paper I shall, furthermore, make a preliminary report upon a new method of studying the mechanism of anaphylaxis and immunity. Hitherto it has been customary to study these phenomena by means of the reaction to antigen, induced through the presence of antibody in the organism. The object sought by the method herein described is to permit of the identification of the antigen, as well as of the antibody, in the sensitized or immunized animal.

The essential feature of this method consists in the use of an immune serum as antigen. To illustrate: if a guinea-pig be sensitized by means of large doses of the serum of a rabbit immunized against horse serum, it has been shown that the passive sensitization to horse serum persists over a period of two weeks. During 
the latter part of this period, however, an active sensitization develops towards rabbit serum. It becomes possible, therefore, to test the same uterus for the presence both of the antigen, and of the antibody thereto. The antigen is revealed by the reaction produced by horse serum, which demonstrates that the rabbit component still persists. The antibody is revealed by the reaction to normal rabbit serum. This condition is illustrated in Fig. I.

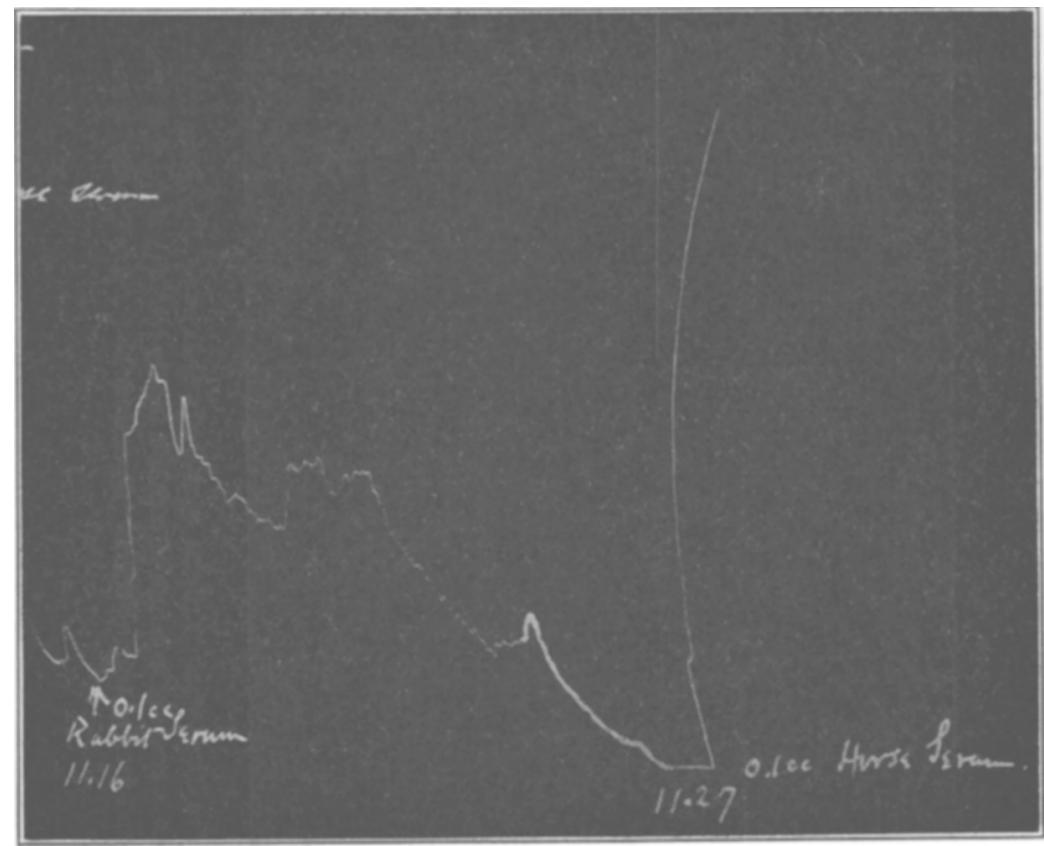

FIG. I. Guinea-pig passively sensitized Jan. 4 by the intraperitoneal injection of 3 c.c. of the serum of a rabbit highly immunized against horse serum. Killed January 15, and uterine tracing taken. Reactions to both rabbit and horse serum.

In the same way, guinea-pigs actively sensitized or immunized against rabbit serum may be partially desensitized by means of an injection of the serum of a rabbit immunized against horse serum. The presence of the antigen in the sensitized cells is revealed by the reaction of the uterus to horse serum, while the reaction to rabbit serum shows that the autogenous antibody also persists. This fact is illustrated in Fig. 2.

The bearing of these data upon the interpretation of certain 

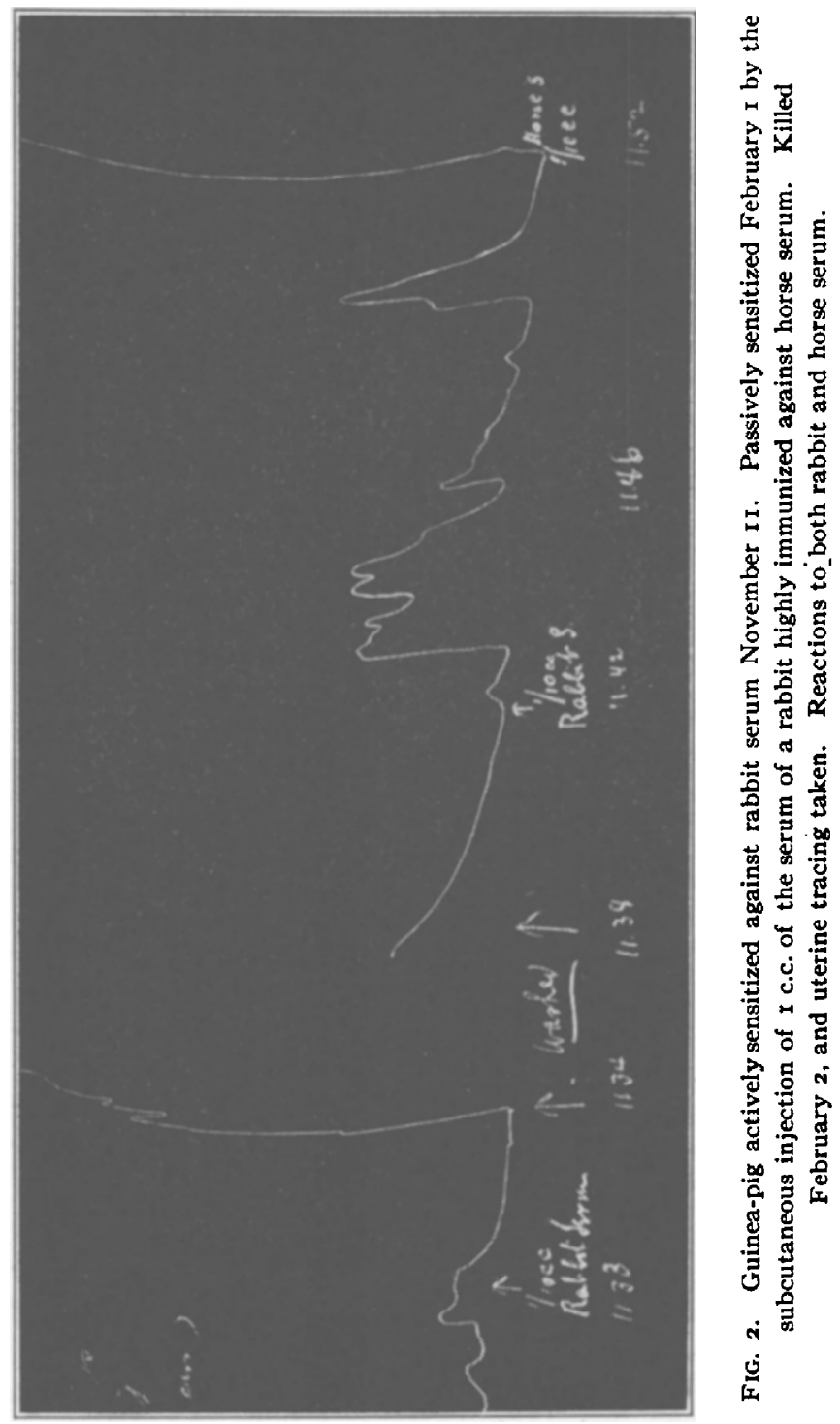
phenomena of anaphylaxis and of immunity depends upon a third fact. It can be shown that a uterine preparation which has been partially desensitized by the addition of antigen is in a refractory, or "anti-anaphylactic" condition. Such a uterus no longer responds to the minute quantities of antigen which were at first effective, but can only be stimulated by relatively enormous amounts of antigen. This shows that the previous addition of antigen markedly lowers the reactivity of the antibody in the cells of the body. This is illustrated in Fig. 3 .

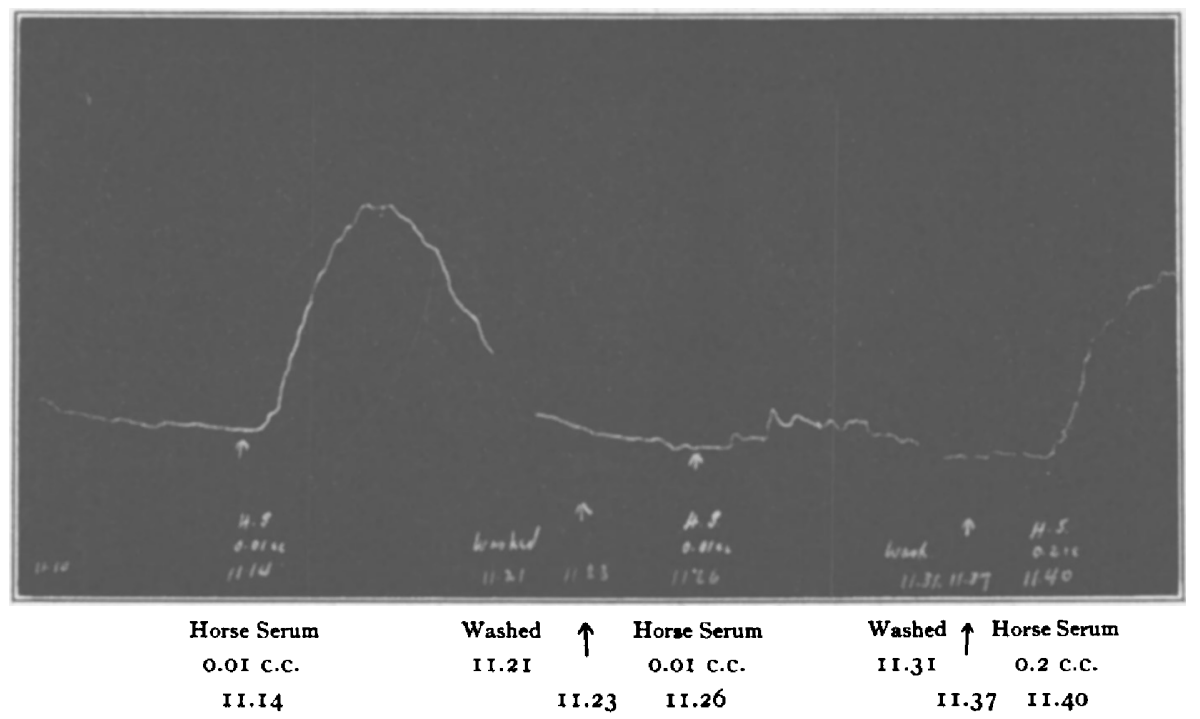

FIG. 3. Guinea-pig actively sensitized against horse serum November $2 \mathrm{I}$. Killed December 12, and uterine tracing taken. After preliminary additions of antigen, the organ responds only to large amounts of the latter.

The conclusion is therefore drawn that the resistance of immunized and of desensitized animals is in very great measure due to the presence of antigen in the cells, which markedly lowers the reactivity of the antibody in these cells. In course of time, by a spontaneous process of reaction, the antigen in the cells is destroyed, and the antibody again exists alone, or in preponderating amount, and the anaphylactic state recurs. In a previous paper I have shown that very large amounts of antibodies in the serum protect a guinea-pig only poorly against anaphylactic shock. The protective value of the antibodies in the blood of an animal 
is, therefore, of relatively slight importance as compared with the presence of antigen in the cells. Therefore, it may be said that just as the presence of antibody in the serum is ineffective in making a guinea-pig hypersensitive, so, too, it fails adequately to explain the mechanism of immunity and of anti-anaphylaxis. The latter phenomenon, likewise, is predominantly cellular, and is due to the presence of antigen in the cell.

\section{Conclusions.}

I. The presence of antibody in the circulating blood alone does not make a guinea-pig hypersensitive. Such a result is achieved only by the presence of antibodies in the cells of the body.

2. The presence of antibody in the blood of the desensitized or of the immunized guinea-pig is only a subsidiary part of the mechanism of protection against anaphylactic shock. The presence of antigen within the cell is the effective factor, which so lowers the reactivity of the cellular antibody that additional antigen fails to produce the characteristic anaphylactic response.

3. By means of a special technique, the coëxistence of antigen and antibody within the same cellular tissue is demonstrated.

\section{$50(867)$}

On the clinical value of the serum skin test in tuberculosis.

\section{BY J. BRONFENBRENNER.}

[From the Pathological and Research Laboratories of the Western Pennsylvania Hospital, Pittsburgh, Pa.]

In the work on Intraperitoneal Lysis of Tubercle Bacilli reported to this society last year by Dr. Manwaring and myself, the conclusion was reached that tubercle bacilli injected in the peritoneal cavity of tuberculous guinea pigs undergo rapid destruction, due to the specific activity of peritoneal tissue cells which apparently did not depend on circulating antibody. In the experiments taken up this year, with the purpose of studying more closely the changes in the blood of tuberculous guinea-pigs, several interesting phenomena were found, to be reported in detail else-

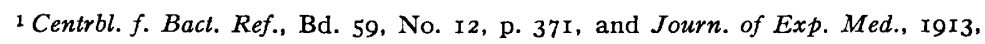
Vol. XVIII, no. 6, p. 60I. 